\title{
MEDIDAS DE BIOSSEGURANÇA EM AUDIOLOGIA
}

\section{Biosafety precautions in audiology}

\author{
Patrícia Cotta Mancini (1), Letícia Caldas Teixeira (2), Luciana Macedo de Resende ${ }^{(3)}$, \\ Adriana Martins Gomes ${ }^{(4)}$, Laélia Cristina Caseiro Vicente ${ }^{(5)}$, Patrícia Marques de Oliveira ${ }^{(6)}$
}

\begin{abstract}
RESUMO
Tema: Biossegurança na atuação audiológica. Objetivo: rever as medidas de precaução-padrão na literatura para o controle de infecção na audiologia. As medidas de biossegurança sugeridas para diversos profissionais de saúde foram adaptadas para as atividades inerentes à prática audiológica no Serviço de Audiologia do Hospital das Clínicas da UFMG. Conclusão: as medidas de precauçãopadrão apresentadas podem ser consideradas e viabilizadas nas diversas instituições, hospitais ou clínicas, nas quais a atuação fonoaudiológica é cada vez mais presente e, por conseguinte, impele medidas de precauções específicas à natureza dos exames audiológicos.
\end{abstract}

DESCRITORES: Audiologia; Controle de Infecções; Exposição a Agentes Biológicos

\section{INTRODUÇÃO}

Biossegurança é o conjunto de ações voltadas para prevenir, minimizar ou eliminar riscos inerentes às atividades de pesquisa, produção, ensino, desenvolvimento tecnológico e prestação de serviços, objetivando preservar a saúde do homem, dos animais e do meio ambiente ${ }^{1}$. Ela consiste em um conjunto de práticas e ações técnicas com preocupações sociais e ambientais destinadas a controlar os

(1) Fonoaudióloga; Professora Assistente do Curso de Fonoaudiologia da Faculdade de Medicina da Universidade Federal de Minas Gerais; Mestre em Lingüística pela Faculdade de Letras da Universidade Federal de Minas Gerais.

(2) Pedagoga; Fonoaudióloga; Professora Assistente do Curso de Fonoaudiologia da Faculdade de Medicina da Universidade Federal de Minas Gerais; Mestre em Educação pela Universidade Federal de Minas Gerais.

(3) Fonoaudióloga; Professora Assistente do Curso de Fonoaudiologia da Faculdade de Medicina da Universidade Federal de Minas Gerais; Mestre em Fonoaudiologia pela Pontifícia Universidade Católica de São Paulo.

(4) Fonoaudióloga; Professora do Curso de Fonoaudiologia do Unicentro Izabela Hendrix e Pontifícia Universidade Católica de Minas Gerais; Mestre em Fonoaudiologia pela Universidade Veiga de Almeida no Rio de Janeiro.

(5) Fonoaudióloga; Professora Assistente do Curso de Fonoaudiologia da Faculdade de Medicina da Universidade Federal de Minas Gerais; Mestre em Distúrbios de Comunicação Humana pela Pontifícia Universidade Católica de São Paulo.

(6) Fonoaudióloga do Hospital das Clínicas da Universidade Federal de Minas Gerais; Mestre em Lingüística pela UFMG. possíveis riscos à saúde oferecidos à equipe da saúde e aos pacientes ${ }^{2}$. Outra definição de biossegurança refere-se à prevenção de acidentes em ambientes ocupacionais, sendo apresentada como o conjunto de medidas técnicas, administrativas, educacionais e médicas empregadas para prevenir acidentes em ambientes biotecnológicos, clínicas e hospitais ${ }^{3,4}$.

No Brasil, a Lei no 9.431 de 6 de janeiro de 1997 dispõe sobre a obrigatoriedade da manutenção pelos hospitais do país de um programa de controle de infecções hospitalares (Portaria no 2.616/MS/GM de 12 de maio de 1998). Sua abrangência é ampla envolvendo relações com a promoção de saúde no ambiente de trabalho, no meio ambiente e na comunidade ${ }^{5}$.

$\mathrm{Na}$ rotina clínica, muitas vezes os indivíduos infectados não podem ser identificados quanto à sua saúde geral. Dessa forma, recomenda-se que medidas e protocolos de controle de infecção dependam do procedimento a ser realizado e não do paciente a ser atendido ${ }^{6}$. A Fonoaudiologia é uma ciência que está vinculada diretamente à saúde do indivíduo, e por isso demanda a adoção de procedimentos de controle de infecção em suas diversas áreas de atuação.

O risco de transmissão de doenças durante a realização de exames auditivos pode ocorrer tanto do paciente para o profissional, quanto do profissional para o paciente, devido à exposição a microrganismos presentes na mucosa auditiva. Para evitar a contaminação dos pacientes bem como do 
examinador, são necessárias algumas medidas direcionadas à prática fonoaudiológica ${ }^{7}$.

Este artigo tem como objetivo rever as medidas de precaução-padrão sugeridas na literatura e adaptá-las para o controle de infecção na prática da audiologia.

\section{MÉTODOS}

A revisão da literatura foi realizada no período de 15 de março a 10 de agosto de 2008, a partir das seguintes bases de dados on-line: LILACS, MEDLINE e Scielo. Essas bases foram acessadas por meio da Biblioteca Virtual em Saúde e Pubmed. Outra estratégia utilizada foi a busca em listas de referências dos artigos identificados e selecionados.

Nessa pesquisa foram utilizados os seguintes descritores: "Hearing Tests", "Speech-Language pathology", "infection control", "sterilization", "disinfection" e "universal precautions", sendo adotados como critérios de inclusão publicações nos idiomas português e inglês e excluídos os artigos publicados em outros idiomas. A seleção dos artigos baseou-se também na conformidade dos assuntos aos objetivos deste trabalho, tendo sido desconsiderados aqueles que, apesar de aparecerem no resultado da busca, não correlacionavam fonoaudiologia e medidas de biossegurança. Por meio da busca em referências bibliográficas dos estudos encontrados, identificaram-se dois estudos que foram incluídos nessa revisão.

Foi ainda realizada pesquisa na Internet por meio de acesso ao site Google correlacionandose os descritores, com a finalidade de ter acesso à legislação brasileira pertinente.

Foram encontradas 32 referências, das quais 21 foram selecionadas por abordarem o tema dessa revisão. Entretanto, uma referência foi excluída por não preencher o critério de idioma estabelecido. Assim, foram incluídas 20 publicações na presente revisão.

\section{REVISÃO DA LITERATURA}

A prática da audiologia expõe fonoaudiólogos e pacientes ao contato com microorganismos. Desta forma, as medidas de biossegurança específicas para o controle de infecção em audiologia não devem ser negligenciadas ${ }^{8}$.

Uma forma segura e eficaz contra a contaminação é a utilização de equipamentos de proteção individual (EPI), que formam barreiras protetoras reduzindo o contato com matérias orgânicas. Seu uso deve ser obrigatório para evitar o contato com sangue e secreções orgânicas ${ }^{8}$. Os EPI básicos recomendados são: luvas, máscaras, jaleco, gorro e protetores oculares ${ }^{8,9}$. Além do uso desses equipamentos, devem ser seguidos os cuidados com imunização feita por meio de vacinas, que reduzem o risco de infecções e programar os cuidados com o ambiente que limita a propagação de microrganismos. Todas essas medidas protegem a saúde da equipe profissional e de seus pacientes ${ }^{6}$.

Nesse artigo será abordado o uso de EPI como jaleco, luvas, sapatos, gorro e ainda as condutas imprescindíveis como lavagem de mãos, cuidados com artigos e o ambiente, além de incluir os cuidados específicos para os procedimentos durante a realização de exames audiológicos.

\section{Jaleco}

O jaleco constitui barreira de proteção para as roupas pessoais devendo ter colarinho alto e mangas longas, podendo ser de pano ou descartável. Alguns autores sugerem os jalecos com mangas que cubram a roupa com comprimento $3 / 4$, mantido sempre abotoado. O jaleco deverá ser utilizado apenas nas dependências da clínica, exclusivamente para o atendimento ao paciente a fim de evitar veiculação de microrganismos da clínica para outros ambientes. Deve ser retirado na clínica e colocado em sacos de plástico para o procedimento posterior (limpeza ou descarte), sendo necessário lavá-los separadamente das roupas de uso pessoal. A cor do jaleco deve ser preferencialmente branca, para facilitar a visualização de sujeiras ${ }^{9}$.

Os jalecos devem ser trocados diariamente, ou sempre que contaminados por fluidos corpóreos. Não se deve sentar sobre bancadas e pias e devese ter o cuidado de não encostar às paredes ou em outros locais prováveis de contaminação. Deve-se ainda evitar roupas de lã, de veludo ou outros tecidos de fibras grossas, pois essas liberam e absorvem milhares de partículas contaminando o usuário e o ambiente ${ }^{9}$.

\section{Luvas}

As luvas são usadas como barreira protetora para evitar o contato com líquidos corporais, secreções e objetos contaminados. As luvas de procedimento (de látex, descartáveis) devem ser trocadas a cada paciente e sempre que ocorrerem furos ${ }^{9}$.

O uso contínuo das luvas acaba por criar um ambiente propício para a proliferação de microorganismos sob o látex. Assim, quando estiver com as mãos enluvadas não se deve manipular objetos fora do campo de trabalho (canetas, fichas clínicas, maçanetas, telefone, etc), mas caso seja necessário, devem ser utilizadas luvas de sobrepor (material plástico) ${ }^{2}$. 
É importante ressaltar que o uso de luvas não exclui a lavagem das mãos e antes de utilizá-las é imprescindível que as mãos estejam limpas. As luvas devem ser retiradas imediatamente após o atendimento, sem que haja toque na parte externa. O descarte deve ser feito em lixo apropriado para material infectante e as mãos devem ser lavadas assim que as luvas forem retiradas ${ }^{2}$.

O tipo de luva varia de acordo com o procedimento realizado. As luvas de procedimento são as indicadas para a rotina diária e as luvas esterilizadas são indicadas para procedimentos invasivos. As luvas são artigos descartáveis e não devem ser reutilizadas, lavadas (lavagem de mãos enluvadas), desinfectadas ou esterilizadas ${ }^{9}$.

\section{Vestuário}

O uso de brincos e anéis não é recomendado durante $o$ atendimento, pois pode haver o acúmulo de microrganismos ${ }^{2}$. Também é importante fazer o uso de sapatos fechados, evitando assim, o contato da pele com os agentes infecciosos ${ }^{2}$.

O gorro proporciona uma barreira efetiva para o profissional, para a sua equipe e para o paciente, pois protege contra gotículas de saliva, aerossol, sangue contaminado e também contra piolhos ${ }^{2,3}$.

\section{Lavagem de mãos}

A lavagem das mãos constitui a ação básica mais importante para prevenção e controle de infecção ${ }^{2,3,9,10}$. A pele é densamente povoada por microrganismos transitórios e/ou residentes, que podem ser facilmente removidos com a adequada lavagem das mãos e/ou degermação das mesmas com o uso de produtos químicos ${ }^{2,9,10}$.

A técnica mais utilizada para a higienização das mãos é a lavagem que consiste na fricção manual vigorosa de toda a superfície das mãos e punhos, utilizando-se sabão/detergente, seguida de enxágüe abundante em água corrente ${ }^{5,9}$. O tempo recomendado para a lavagem das mãos é de aproximadamente 15 segundos e está indicada após o contato com fluidos e secreções ${ }^{5,9}$, antes de calçar as luvas e após removê-las, antes e depois de atos fisiológicos, entre contatos com pacientes e antes de procedimentos no paciente $3,5,6,9-11$.

A lavagem rotineira das mãos deve ser feita como se segue $5,9,12$ :

1 - Retirada de anéis, relógios e pulseiras;

2 - Ensaboar as mãos e metade do antebraço, no mínimo, 15 segundos. O sabão deve ser idealmente líquido e hipoalergênico;

3- Abrir a torneira e molhar as mãos sem encostar-se à pia;
4 - Dispersar o sabão (6 a $8 \mathrm{ml}$ ) pelas palmas das mãos, com movimentos circulares;

5 - Ensaboar o dorso da mão com movimentos circulares;

6 - Friccionar os espaços interdigitais deslizando uma mão sobre a outra;

7 - Friccionar as articulações de uma mão com o auxilio da outra;

8 - Friccionar o polegar de uma mão com o auxilio da outra;

9 - Friccionar as unhas e extremidades dos dedos de uma mão na palma da outra com movimentos circulares;

10 - Friccionar a metade do antebraço de uma mão com o auxilio da outra;

11 - Enxaguar as mãos da extremidade dos dedos em direção ao antebraço, retirando totalmente o resíduo do sabão;

12 - Enxugar as mãos com papel toalha e/ou dispositivo eletrônico de ar quente;

13 - As mãos devem estar secas completamente. A secagem adequada pode ser o primeiro passo na prevenção de irritações na pele;

14 - Fechar a torneira utilizando papel toalha.

A rotina de lavagem das mãos deve ser feita em pias exclusivamente para esta finalidade, sendo recomendada a instalação de pia, sabonete líquido e papel toalha no consultório. Profissionais com lesões ou dermatites nas mãos e unhas devem abster-se de atendimentos que manipulem instrumentos e aparelhos potencialmente contaminados ${ }^{9}$. Deve-se sempre manter as unhas curtas, evitando acúmulo de microrganismos. O uso de esmaltes escuros deve ser evitado, pois impossibilita a visualização de sujeiras ${ }^{2}$.

\section{Higienização do ambiente e dos artigos}

$\mathrm{Na}$ área da saúde, os cuidados quanto à esterilização ou à desinfecção de superfícies ou instrumentos são importantes para o controle de infecção. As possibilidades de infecção poderão ser reduzidas se o profissional, independentemente de sua especialidade, distinguir o ambiente de atuação e o risco potencial de transmissão dos instrumentos e materiais utilizados ${ }^{3}$.

A esterilização é a destruição ou remoção de todas as formas de vida de um dado material. Consiste na completa eliminação ou destruição das formas de microrganismos. Esse processo pode ser físico ou químico. É o método mais eficiente de controle de infecção, seu uso deve ser recomendado como rotina, sendo a autoclavagem o método mais seguro ${ }^{9,12,13}$.

A desinfecção é a destruição dos microrganismos patogênicos, sem que haja, necessariamente 
a destruição de todos os microrganismos; ocorre a diminuição do número de microrganismos em dado local ou material, reduzindo-o a uma quantidade segura $3,9,12,13$.

\section{Classificação dos artigos}

O Ministério da Saúde, através do Manual de Controle de Infecção Hospitalar ${ }^{13}$, recomendou a classificação de Spaulding ${ }^{14}$ para objetos inanimados, conforme o risco potencial de transmissão de infecção que apresentam. Nessa classificação, os materiais são considerados como artigos críticos, semi-críticos e não-críticos.

Artigos críticos são todos aqueles que penetram nos tecidos subepiteliais, no sistema vascular e em outros órgãos isentos de microbiota própria, bem como todos aqueles que estejam conectados com eles, como, por exemplo, instrumentos de corte ou com ponta. Esses artigos devem estar obrigatoriamente esterilizados ao serem utilizados ${ }^{13}$.

Artigos semi-críticos são todos aqueles que entram em contato apenas com mucosa íntegra, capaz de impedir a invasão nos tecidos subepiteliais. Esses artigos também devem estar esterilizados, e a desinfecção é aceita apenas para os itens que não podem ser esterilizados por procedimentos físicos ${ }^{13,15}$.

Artigos não-críticos são aqueles que entram em contato com a pele íntegra e ainda os que não entram em contato direto com o paciente. Esses artigos devem sofrer procedimentos de desinfecção ${ }^{13}$.

$\mathrm{Na}$ audiologia são utilizados artigos não-críticos (eletrodos, cuba, fones, cânula para irrigação) e artigos considerados semi-críticos (espéculos e olivas). Deste modo, a limpeza desses materiais deve ser realizada através dos processos de desinfecção ou esterilização ${ }^{13}$.

A rotina de limpeza deve seguir as seguintes etapas ${ }^{2}$ :

1 - Imersão: Esta etapa objetiva a remoção das sujeiras e resíduos orgânicos, pela ação da água e sabão ou detergentes;

2 - Enxágüe: Realizado após a limpeza com água corrente e potável;

3 - Secagem: Deve ser realizado com pano limpo, secador de ar quente/frio ou ar comprimido medicinal.

A pia para lavagem de artigos deve ser separada daquela usada para lavagem das mãos ${ }^{5,9}$.

Os artigos fonoaudiológicos esterilizados e/ou desinfectados devem ser guardados adequadamente, evitando a sua contaminação. O local da armazenagem deve ser limpo, protegido do meio externo, utilizado exclusivamente para esse fim ${ }^{9}$. Segundo estudo ${ }^{16}$, muitas vezes os materiais este- rilizados ou desinfectados são guardados em recipientes não-estéreis favorecendo sua contaminação, bem como do paciente. Uma medida eficaz sugerida na literatura para minimizar o risco de adquirir uma infecção através de instrumentos contaminados seria o uso de utensílios descartáveis tais como cuba, olivas e espéculos ${ }^{16-18}$.

\section{Cuidados com Ambiente}

Superfícies fixas (pisos, paredes, tetos, portas, mobiliários e demais instalações) não representam riscos significativos de contaminação. Portanto, a desinfecção rotineira dessas superfícies torna-se necessária apenas quando houver depósito ou respingo de matéria orgânica ${ }^{9}$.

Os locais que contêm matéria orgânica podem causar riscos a pacientes e profissionais de saúde e necessita de descontaminação, sendo necessário o uso de EPI durante o processo de limpeza (luvas de borracha e botas de polietileno) ${ }^{9}$.

O revestimento de paredes, pisos e tetos devem ser resistentes à lavagem e ao uso de desinfetantes e ter o menor número de frestas e ranhuras possível. As tintas utilizadas em paredes e tetos devem ser resistentes à lavagens e ao uso de desinfetantes ${ }^{9}$.

O mais adequado nas instituições de saúde é que os ambientes sejam bem iluminados e arejados por meio de janelas, não sendo recomendado o uso de ventiladores, pois estes causam a elevação das partículas de poeira no ambiente ${ }^{9}$.

\section{Biossegurança na prática audiológica}

Para evitar a contaminação do próximo paciente bem como do examinador são necessários alguns cuidados específicos durante a realização de exames audiológicos ${ }^{7}$. Os aparelhos usados para esses exames entram em contato com a pele do indivíduo podendo assim ser contaminado com a flora microbiana presente no pavilhão auditivo e/ou meato acústico externo (fones, eletrodos, cânula de irrigação, espéculos ou olivas) ${ }^{15,16,18}$. Sendo assim, é recomendado utilizar meios de descontaminação como limpeza, desinfecção ou esterilização que torne esses equipamentos reutilizáveis, sendo seguros quanto à possibilidade de transmissão da flora indígena e patógena de um paciente para outro, obedecendo assim o princípio da biossegurança ${ }^{7}$.

O cerume somente é considerado um agente infeccioso se estiver em contato com sangue ou muco. Entretanto, sua coloração e consistência dificultam a detecção dessas substâncias orgânicas. Por isso, devido ao seu grande potencial de contaminação, o cerume deve ser sempre tratado 
como substância infecciosa pela impossibilidade de determinar visualmente a sua composição ${ }^{7,15}$.

Os serviços de audiologia são procurados por uma enorme variedade de pacientes geriátricos, diabéticos, pediátricos e HIV positivos, que possuem imunidade comprometida e com risco potencial para infecções oportunistas ${ }^{17,19}$. Na última década os pacientes HIV positivos foram identificados como pacientes de risco para desenvolverem perdas auditivas devido à terapia antiretroviral, que contém substâncias potencialmente ototóxicas. Embora o risco de transmissão do HIV durante os exames audiógicos seja remoto, esses pacientes imunodeprimidos não devem ser expostos a qualquer risco de contaminação $7,9,17,19$.

Na realização de todos os exames audiológicos, as medidas de biossegurança como lavagem das mãos no início e final do atendimento, uso de jaleco, luvas, cabelo preso, sapatos fechados e unhas curtas devem ser mantidos regularmente. Entretanto, devido às peculiaridades de cada exame, alguns cuidados adicionais são necessários ${ }^{7}$. As medidas de biossegurança serão apresentadas levando em consideração as particularidades dos procedimentos, sendo adaptadas as condutas sugeridas na literatura para cada exame audiológico.

\section{Audiometria e Imitanciometria}

Os artigos utilizados na audiometria e imitanciometria são classificados como semi-críticos e nãocríticos ${ }^{13}$, mas nem por isto sua desinfecção deve ser negligenciada. Todos os materiais manipulados na audiometria e na imitanciometria devem ser limpos com eficiência, pois já se sabe que materiais infectados são vias de grande contaminação, tanto para quem os manipula quanto para quem os utiliza ${ }^{7}$.

De acordo com as medidas de biossegurança citadas na literatura, sugerimos algumas condutas que devem ser tomadas no sentido de garantir a preservação da limpeza dos artigos desinfectados, além de minimizar a possibilidade de propagação de microorganismos presentes nos materiais já utilizados 2,5 :

- As olivas e espéculos limpos deverão ser guardadas em potes com tampa, com identificação e data de desinfecção;

- Manter as gazes em recipientes fechados com tampa;

- Utilizar luvas para manipulação dos espéculos e olivas, como forma de minimizar os riscos de infecção cruzada;

- Realizar a limpeza do otoscópio, da sonda e do fone do imitanciômetro, entre um paciente e outro utilizando fricção com álcool a 70\%;
- O material descartável utilizado (gaze, luvas) deve ser desprezado em saco de lixo branco leitoso, com o símbolo de infectante ${ }^{9}$.

Os fones de ouvido devem ser desinfectados com álcool a $70 \%$, friccionando por 30 segundos logo após o atendimento. Este procedimento deve ser realizado também no aro dos fones ${ }^{13}$.

O otoscópio deve ser desinfectado com álcool a $70 \%$, friccionando por 30 segundos após cada paciente ${ }^{13}$.

Os espéculos e olivas devem ser preferencialmente descartáveis ${ }^{16-18}$. Diante dessa impossibilidade, os espéculos e olivas devem ser desprezados em recipiente com água e sabão para posteriormente serem desinfectados (imersão em glutaraldeído a $2 \%$ por 20 a 30 minutos) ${ }^{18,20}$ ou esterelização (autoclave a vapor) ${ }^{13,20}$

No aparelho de vibração óssea, sugere-se a desinfecção com álcool a 70\%, fricção por 30 segundos após cada atendimento ${ }^{13}$.

Os brinquedos para realização de audiometria condicionada devem ser preferencialmente de material lavável, como os de plástico, sendo limpos com água e sabão e desinfectados com álcool a $70 \%$, friccionando por 30 segundos ${ }^{13}$.

É importante ressaltar que o glutaraldeído é uma substância que apresenta ação fungicida, bactericida e viruscida em 10 minutos, tuberculicida em 30 minutos e esporicida em 10 horas e ainda tem a vantagem de não alterar borrachas e plásticos, sendo considerada uma substância adequada para a desinfecção dos objetos utilizados durante os exames audiológicos ${ }^{18}$. Entretanto, o glutaraldeído não deve ser utilizado em ambientes com pouca ventilação (como as cabines) devido à toxidade desta substância ${ }^{13,18}$.

\section{BERA}

O BERA é um exame realizado com o paciente deitado em uma maca. São utilizados eletrodos e um fone para a realização do exame. Deste modo, as medidas de biossegurança sugeridas na literatura devem ser adaptadas a este procedimento, sendo recomendado ${ }^{7,13}$ :

- Trocar os lençóis ou cobrir a maca com papel descartável;

- Realizar a limpeza dos eletrodos e do fone com gaze embebida em álcool $70 \%$ durante 30 segundos após cada atendimento;

- Manter os recipientes de gazes fechados com tampa;

- O material descartável utilizado (gaze, luvas) deve ser desprezado em saco de lixo branco leitoso, com o símbolo de infectante;

- Limpar o colchão com água e sabão no início e final do dia. 
Novas pesquisas devem ser realizadas a fim de investigar quais substâncias são benéficas para a limpeza dos eletrodos e fones de ouvido, bem como para a preservação da vida útil dos mesmos.

\section{Teste Vestibular}

Os materiais utilizados para a realização dos exames vestibulares são eletrodos, cuba (usada para recolher a água), cânula (para irrigar a orelha externa) e vasilhame (usado para recolher o vômito do paciente, caso ocorra). Dependendo do material de que são feitos e do tipo de contato que têm com o paciente dá-se o processo de limpeza/desinfecção desses objetos. As medidas de biossegurança sugeridas para a realização deste exame são ${ }^{13}$ :

- O colchão deve ser protegido por uma capa impermeável à água e devem ser usados lençóis adicionais;

- Os lençóis devem ser trocados a cada paciente;

- Realizar a limpeza dos eletrodos e da cânula de irrigação com gaze embebida em álcool $70 \%$ durante 30 segundos após cada exame;

- O material descartável utilizado (gaze, luvas) deve ser desprezado em saco de lixo branco leitoso, com o símbolo de infectante;

- Cuba e vasilhame - o ideal é que sejam descartáveis ${ }^{16}$. Diante dessa impossibilidade a cuba e vasilhame deverão ser limpos com água e sabão (detergente neutro), posteriormente desinfectados com álcool $70 \%$ através de imersão por 10 minutos e em seguida realizar esterilização (autoclave ou estufa).

No ambiente onde é executado o Teste Vestibular deve-se realizar a limpeza de manutenção, que é feita com água e sabão. O computador e a mesa onde este é colocado devem ser limpos com pano úmido ${ }^{13}$.

É fundamental que haja remoção mecânica da sujidade ou da matéria orgânica. A armação da maca deve estar incluída nas escalas de limpeza e deve ser limpa com um pano e uma solução detergente e seco a seguir. A maca deve ser protegida por uma capa impermeável à água e sua limpeza só será necessária caso esteja suja ou contaminada. Uma limpeza completa com um pano e uma solução detergente, deixando a superfície secar totalmente em seguida, é geralmente suficiente ${ }^{13}$.

Se um paciente tiver reflexo de vômito durante o exame, a matéria orgânica deverá ser depositada no piso ou ser jogada em um recipiente (o vasilhame deve estar sempre presente no local do exame e de preferência ser descartável), e as etapas da limpeza e desinfecção deste local serão: retirar a matéria orgânica com pano ou papel-toaIha; realizar limpeza do local com água e sabão; enxaguar; espera secar; aplicar o desinfetante; e remover o desinfetante com pano úmido. Agentes antimicrobianos podem ser algumas vezes incorporados às soluções de limpeza, sem serem descritos como desinfectantes, mas seu uso deve ser evitado sempre que possível para não levar à seleção de microrganismos mais resistentes ${ }^{9,13}$.

Novas pesquisas deverão ser realizadas com o objetivo de averiguar se as substâncias sugeridas na literatura para desinfecção dos equipamentos não limitam sua vida útil ou mesmo se prejudicam o seu funcionamento, como, por exemplo, a captação de potencias pelos eletrodos.

\section{Emissões Otoacústicas}

Este exame pode ser realizado em ambiente hospitalar ou ambulatorial. A limpeza indicada para o ambiente hospitalar está relacionada com a freqüência e abrangência necessária, devendo ser respeitadas as normas de biossegurança preconizadas pelo programa de controle de infecção hospitalar. Quando esses testes ocorrem em ambulatórios ou clínicas, deverá ser realizada a limpeza de manutenção, que é destinada a áreas de alta rotatividade de atendimento ou procedimentos, com o objetivo de manter durante todo o período de trabalho um ambiente agradável e seguro ${ }^{13}$.

De acordo com a literatura, sugere-se ainda tomar os seguintes cuidados adicionais ${ }^{2,13}$ :

- Manipular as olivas sempre com luvas descartáveis;

- As olivas devem ser acondicionadas em sacos plásticos ou potes com tampa para serem enviadas para desinfecção;

- O material descartável utilizado (gaze, luvas) deve ser desprezado em saco de lixo branco leitoso, com o símbolo de infectante.

$\mathrm{Na}$ clínica fonoaudiológica deve-se utilizar instrumentos descartáveis tais como olivas, espéculos e cubas quando possível ${ }^{16,18}$. Os artigos desinfetados ou esterilizados devem ser acondicionados adequadamente para evitar a sua contaminação. $\mathrm{O}$ local da armazenagem deve ser preferencialmente estéril ${ }^{16}$, protegido do contato com o meio externo e que seja utilizado somente para este fim. Seguindo estes cuidados, a esterilização mantém-se por sete dias. Passado este período, o material precisa ser reprocessado ${ }^{13}$.

\section{COMENTÁRIOS FINAIS}

Após a realização dessa pesquisa, vários procedimentos e medidas de biossegurança foram incluídos na rotina de atendimento do serviço de audiologia do Hospital das Clínicas da UFMG, dentre os quais pode-se destacar: 
- Uso de luvas durante a realização da meatoscopia e dos exames de imitanciometria, emissões otoacústicas e teste vestibular;

- Utilização de álcool $70 \%$ nos fones supra-aurais após a realização da audiometria, imitanciometria e BERA;

- As olivas foram descartadas em recipientes com tampa;

- Uso de luvas no manuseio de todo material utilizado no paciente;

- Foram reforçadas algumas medidas adotadas anteriormente como lavagem das mãos no início e final do atendimento, uso de jaleco, cabelo preso e unhas curtas, por meio de cartazes afixados nas salas de atendimento;

- Os procedimentos necessários e recomendados para limpeza do ambiente foram esclarecidos ao pessoal responsável pela mesma.

Novas pesquisas devem ser realizadas no sentido de identificar os agentes infecciosos presentes em equipamentos utilizados na rotina audiológica, além de verificar se as medidas de biossegurança adotadas são eficazes na redução ou eliminação da exposição do fonoaudiólogo e de seus pacientes a microorganismos patogênicos.

A maioria dos autores consultados aborda as medidas de precaução-padrão voltadas para hospitais e consultórios odontológicos, sendo encontrados poucos estudos que relatam as medidas de precaução específicas para a atuação fonoaudiológica. Observou-se que o uso de materiais descartáveis tais como espéculos, olivas e cubas, vem sendo uma rotina adotada em vários serviços de otorrinolaringologia internacionais para minimizar o risco de contaminação do paciente e do examinador.

As medidas de precaução-padrão sugeridas neste artigo são baseadas principalmente nas diretrizes da Agência Nacional de Vigilância Sanitária (ANVISA), na legislação brasileira para o controle de infecção hospitalar e em condutas sugeridas em artigos científicos estrangeiros. Portanto, tais medidas devem ser consideradas e viabilizadas nas diversas instituições, clínicas ou hospitais na qual a atuação fonoaudiológica é cada vez mais presente $e$, por conseguinte impele medidas de precauções específicas à natureza dos exames audiológicos.

\begin{abstract}
Background: biosafety precautions for audiologic practice. Purpose: to review the biosafety precautions suggested in the literature for infection control in audiology. The biosafety precautions suggested for many health professionals were adapted for the inherent activities of audiologic practice in Audiology Service at Hospital das Clínicas of UFMG. Conclusion: the submitted biosafety precautions can be used by any institution, hospital or clinic where the audiologic performance is becoming more widespread and, consequently, demanding specific precautions for audiologic practice.
\end{abstract}

KEYWORDS: Audiology; Infection Control; Exposure to Biological Agents

\section{REFERÊNCIAS}

1. Teixeira $P$, Valle $S$. Biossegurança: uma abordagem multidisciplinar. Rio de Janeiro: Fiocruz; 1996. 2. Souza CP, Tanigute CC, Tipple AFV. Biossegurança: medidas de precauções-padrão em fonoaudiologia. Fonoaudiol Bras. 2000; 3(4):18-24.

3. Faculdade de Odontologia de Bauru - FOB / USP. Manual de biossegurança. [periódico on line] 2000. Disponível em: URL: http://www.fob.usp. br/adm/comissoes/bioseg/

4. Teixeira M, Santos MV. Responsabilidade no controle de infecção. Rev Assoc Paul Cirur Dent. 1999; 53(3):177-89.

5. Brasil. Ministério da Saúde. Portaria oㅡ 2.616/MS/ GM, de 12 de maio de 1998. Institui, no âmbito do
Ministério da Saúde, o Processamento de Artigos e Superfícies em Estabelecimentos de Saúde [periódico online]. Disp. http://www.anvisa.gov.br/ legis/portarias/2616_98.htm.

6. Center for Disease Control and Prevention CDC. Recommendations Infection Control Practice for Dentistry. Morbidity and Mortality Weekly Report, Atlanta. 1993 May; 42, n.RR-8: 1-12.

7. Kemp RJ, Roeser RJ, Pearson DW, Ballachandra BB. Infection control for the professions of audiology and speech language pathology. Olathe: Iles Publications; 1996.

8. Garner JS. Guideline for isolation precaution in hospitals. Part 1. Evolution of isolations practices. Hospital Infection Control Practices Advisory Committee. 1996; 24(1):24-31. 
9. Brasil. Ministério da Saúde. Secretaria de Políticas de Saúde, Coordenação Nacional de DST e Aids. Controle de infecções na prática odontológica em tempos de aids: manual e condutas. Brasília; 2000.

10. Panhotra BR, Saxena AK, Al-Mulhim AS. Contamination of patients' files in intensive care units: an indication of strict handwashing after entering case notes. Am J Infect Control. 2005 Sep; 33(7):398-401.

11. Molinari JA, Merchant VA, Gleason MJ. Controversies in infection control. Dent Clin North Am. 1990; 34(1):55-69.

12. Stier CJN. Rotinas em controle de infecção hospitalar. Curitiba: Netsul; 1995.

13. Brasil. Secretaria de Assistência à Saúde. Processamento de artigos de superfícies em estabelecimento de saúde. 2. ed. Brasília; 1994.

14. Spaulding EH. Chemical disinfection of medical and surgical materials. In: Lawrence CA, Block SS. Disinfection, sterilization and preservation. Philadelphia: Lea \&Febinger; 1968. p. 517-31.
15. Ahmad N, Etheridge C, Farrington M, Baguley DM. Prospective study of the microbiological flora of hearing aid moulds and the efficacy of current cleaning techniques. J Laryngol Otol. 2007 Feb; 121(2):110-3.

16. Powell S, Perry J, Meikle D. Microbial contamination of non-disposable instruments in otolaryngology out-patients. J Laryngol Otol. 2003 Feb; 117(2):122-5.

17. Hoare S. HIV infection in children--impact upon ENT doctors. Int J Pediatr Otorhinolaryngol. 2003 Dec; 67(Suppl1):S85-90.

18. Muscarella LF. Prevention of disease transmission during flexible laryngoscopy. Am J Infect Control. 2007 Oct; 35(8):536-44.

19. Wolfe TR. The risk of patient cross-contamination from Venturi-Principle atomizers. ORL Head Neck Nurs. 2005 Spring; 23(2):25-7.

20. Dawson CJ, Nielsen R, Dawson DE. Best practice forum: standard high level disinfection protocol development. ORL Head Neck Nurs. 2004 Winter; 21(2):18-21.

RECEBIDO EM: 30/05/2007

ACEITO EM: 17/07/2008

Endereço para correspondência:

Av. Alfredo Balena, 190 sala 3005

Belo Horizonte - MG

CEP: $30130-100$

Tel/Fax: (31) 3248-9950

E-mail: pmancini@medicina.ufmg.br / patmancini@gmail.com 